\title{
CUSTOMER RELATIONSHIP HOTEL CAKRA KUSUMA YOGYAKARTA DALAM MENINGKATKAN KEPUASAN PELANGGAN
}

\author{
Maya Dwi Astuti / Christina Rochayanti / Sigit Tri Pambudi \\ Jurusan Ilmu Komunikasi FISIP UPN "Veteran" Yogyakarta \\ Jl. Babarsari No. 2 Tambakbayan Yogyakarta, Telp. (0274) 485268 \\ Hp.085292174564/ e-mail:madiastuti@yahoo.com
}

\begin{abstract}
Respect of customer relations to build stood in with customers. Utilizes organizational communication study to see the importance for function public relations in an organization. Revenue born out that to fulfill customer satisfaction with be customer relations activity. Customer with customer or customer aspirant. It is prime key in Cakra Kusuma Yogyakarta's Hotel success program in to fulfill customer satisfaction. Final conclusion from this be task implementation and staffs and employees obligation to each in customer relations that do in a professional by employees Cakra Kusuma Yogyakarta's Hotel valid until general manager. Customer relations implementation that consistent and openness communication and interactive with customer or customer aspirant. It is prime key in Cakra Kusuma Yogyakarta's Hotel success program in to fulfill customer satisfaction.
\end{abstract}

Key words: customer relations, hotel, customer satisfaction.

\section{Pendahuluan}

Pesatnya perkembangan demokrasi dan kemajuan dunia industri saat ini menyebabkan perubahan dan kemajuan yang luas di segala bidang, tidak hanya dalam bidang perdagangan dan perniagaan tetapi juga dalam bidang politik, ekonomi, sosial, budaya, pertahanan, dan keamanan. Sejalan dengan perkembangan tersebut, dunia pariwisata mengalami banyak perkembangan terutama di Yogyakarta. Strategi dan pelaksanaan customer relation suatu hotel memegang peranan penting dalam mewujudkan kepuasan pelanggan akan pelayanan suatu hotel karena pada saat pelanggan puas, mereka akan dengan senang hati menyampaikannya kepada orang lain. Sifat dasar manusia adalah adalah ingin mencoba sesuatu yang baru apalagi hal baru ini berasal dari rekomendasi orang terdekat seperti teman atau keluarga. Pelanggan yang puas akan datang lagi dan bahkan akan membawa serta seluruh temannya atau keluarganya. Dengan terciptanya kepuasan pelanggan ini nantinya akan memberikan manfaat antara lain, hubungan hotel dengan pelanggan menjadi harmonis, reputasi hotel menjadi baik di mata pelanggan. Begitupun sebaliknya apabila suatu hotel tidak memperhatikan pelanggannya, maka hal ini akan membawa dampak yang akan merugikan hotel itu sendiri. Harapan adalah kunci pokok bagi setiap pelaku bisnis yang terlibat dalam kepuasan pelanggan. Penulis memiliki ketertarikan untuk melihat, mengamati dan meneliti berawal dari rekomendasi seorang informan yang mengatakan bahwa keluarganya menginap di Hotel Cakra Kusuma selama beberapa hari dalam rangka menghadiri wisuda anaknya. Selama menginap di Hotel Cakra Kusuma mereka mendapat pelayanan yang ramah, cepat, dan mendapatkan suasana yang nyaman. Hotel berbintang tiga ini selain terletak di kawasan yang strategis yaitu jalan Kaliurang dengan berbagai kemudahan fasilitas yang ada, berdekatan dengan kampus UGM serta yang paling berkesan adalah keramahtamahan dan pelayanan yang baik dari seluruh pegawai dan para karyawannya mulai dari satpam, front office, dan dan pihak manajemen yang menerapkan slogan "care and 
smile" kepada setiap pengunjung yang datang.

Diambilnya Hotel Cakra Kusuma sebagai tempat penelitian karena beberapa faktor yaitu lokasi hotel yang strategis, banyak hotel pesaing yang berada di sekitar hotel Cakra Kusuma misalnya Hotel Vidi, Hotel Ishiro dan Hotel Cakra Kembang. Pengunjung hotel selalu ramai apalagi jika waktu akhir pekan, hari libur nasional, maupun saat wisuda universitas. Hal ini dapat diketahui dari parkir hotel yang terlihat penuh pada waktu-waktu tersebut Keberadaan public relations suatu hotel sangat dibutuhkan untuk membina hubungan baik dengan para tamu maupun calon tamu hotel. Selain itu fungsi public relations hotel memiliki fungsi untuk menjaga hubungan baik antara hotel dengan segala pihak yang berkepentingan agar dapat menyamakan opini yang bersifat positif terhadap reputasi hotel. Public Relations memilki peran penting dalam keberhasilan kegiatan perusahaan. Berdasarkan kemampuan yang dimiliki Public Relations, bagi perusahaan yang hendak melakukan tindakan bisnis dari membangun relasi, hingga terciptanya citra sangat perlu peran dari Public Relations. Menurut Scoot M. Cutlip dan Allen H Centre dalam Effective Public Relations adalah: "Public Relations adalah fungsi manajemen yang menilai sikap publik, mengidentifikasi kebijaksanaan dan tata cara organisasi demi kepentingan publiknya, serta merencanakan suatu program kegiatan dan komunikasi untuk memperoleh pengertian dan dukungan publiknya (Ruslan,2006:25).

Kegiatan Public Relations dalam programnya untuk membina hubungan baik dengan pelanggan (customer relations) diharapkan dapat meningkatkan kepuasan terhadap pelanggan, karena kepuasan pelanggan menjadi tujuan utama dari perusahaan untuk meningkatkan citra dan loyalitas pelanggan, salah satu tindakan perusahaan yang dapat dilakukan dalam memuaskan pihak pelanggan yaitu dengan memberikan pelayanan yang baik dalam menanggapi segala komplain dari pihak pelanggan dengan melakukan hubungan baik dengan pelanggan (customer relations). Kenyataan bahwa adanya masalah-masalah yang tidak tertangani dengan baik, munculnya pesaing-pesaing baru, dan gencarnya promosi perusahaan lain dapat menyebabkan suatu perusahaan ditinggalkan oleh pelanggannya menjadi dasar pemikiran setiap pihak pengelola perhotelan untuk lebih meningkatkan perhatian terhadap kebutuhan, keinginan, dan harapan dari para pelanggan. Bagi Hotel Cakara Kusuma, semua karyawan dan semua bagian adalah public relations yang bertugas untuk membentuk opini public yang positif dari semua pelanggan yang datang ke hotel. Pihak Hotel Cakra Kusuma menganggap bahwa apabila semua karyawan yang melaksanakan fungsi dan tugas public relations maka hasilnya dirasakan akan lebih efektif. Pelaksanaan customer relations dalam upaya meningkatkan kepuasan pelanggan adalah dengan menjaga kepercayaan pelanggan terhadap pelayanan hotel membuat peneliti tertarik untuk meneliti tentang pelaksanaan customer relations Hotel Cakra Kusuma Yogyakarta dalam upaya meningkatkan kepuasan pelaggan, peneliti mencoba untuk mengetahuibahwa khalayak yang menjadi pengunjung hotel yang dijadikan target sebagai pelanggan memang merasakan kepuasan terhadap customer relations yang diterapkan Hotel Cakra Kusuma Yogyakarta.

Teori yang digunakan dalam penelitian ini adalah menggunakan Relationship Management Theory dari John Ledingham dan Steven Burning dalam Today's Public Relations (Heath, 2006: 202). Teori ini menyoroti bentuk hubungan serta manajemen yang dilakukan organisasi terhadap Market, Audience, dan Public (MAP). Inti dari teori manajemen relasi adalah fokus kegiatan relasi serta manajemen kegiatan relasi organisasi terhadap MAP. Kunci kegiatan manajemen relasi adalah pada kepercayaan, keterbukaan, dan penerimaan baik. Ada tiga tipe dari hubungan dalam Relationship Management Theory yaitu interpersonal, professional, dan komunitas.

Teori Word Of Mouth Communication adalah komunikasi interpersonal antara dua bahkan lebih individu seperti anggota kelompok referensi atau konsumen dan tenaga penjual (Assael 100 : 1998). Semua orang memiliki pengaruh atas pembelian terus menerus melalui suatu komunikasi. Rekomendasi dari mulut ke mulut merupakan salah satu faktor penting yang berpengaruh terhadap keputusan seseorang dalam membeli suatu produk atau jasa. Word of Mouth lebih berperan dalam perkembangan pasar suatu 
bisnis jasa dibandingkan bisnis produk. Hal ini dikarenakan pada "Bisnis jasa sangat sulit untuk mengetahui faktor kualitas baik sebelum maupun sesuadah pembelian, di mana ciri-ciri jasa adalah bersifat abstrak" Gremler (Assael, 101:1998). Dari beberapa alat komunikasi pemasaran yang ada, bentuk word of mouth merupakan alat promosi yang dominan dalam menunjang pemasaran seperti pemasaran suatu produk atau jasa yang mempunyai resiko tinggi selain dari alat promosi lainnnya. Seperti halnya dengan perusahaan jasa pada umumnya, calon konsumen jasa umumnya akan lebih percaya terhadap cerita atas pengalaman telah menjadi konsumen suatu perusahaan jasa dibandingkan slogan yang disampaikan melalui iklan.

Dengan demikian dapat dikatakan bahwa pemasaran jasa, seperti pemasaran jasa suatu hotel akan lebih bermanfaat bila dilakukan melalui word of mouth, artinya hotel harus memberikan pelayanan yang terbaik bagi setiap pelanggan dan calon pelanggannya agar si pelanggan tersebut menceritakan kepuasan yang dialaminya tersebut kepada rekan dan keluargannya. Pelanggan yang merasa puas terhadap produk dan pelayanan yang diberikan akan membawa keuntungan bagi pihak hotel, yaitu menjadi pelanggan yang setia dan bisa melakukan komunikasi berupa word of mouth (WOM ) positif pada orang lain yang berpotensi besar menjadi pelanggan baru bagi perusahaan.

\section{Metode Penelitian}

Penulis menggunakan metode kualitatif, menurut Bogdan dan Taylor definisi dari metodologi kualitatif yaitu "sebagai prosedur penelitian yang menghasilkan data deskriptif berupa kata-kata tertulis atau lisan dari orangorang dan perilaku yang dapat diamati” (dalam Moleong, 2005: 4). Metode yang digunakan oleh penulis adalah metode deskriptif, data yang diperoleh adalah berupa kata-kata, gambar, dan tidak berupa angka-angka. Dengan demikian, laporan penelitian berupa kutipan-kutipan data untuk memberi gambaran penyajian laporan. Data tersebut berasal naskah wawancara, dokumen pribadi, dokumen resmi, foto, situs resmi, surat kabar, kliping dan dokumen lainnya yang mendukung. Hal ini bertujuan untuk mengetahui pelaksanaan Customer Relations Hotel Cakra Kusuma Yogyakarta dalam meningkatkan kepuasan pelanggan. Data yang digunakan adalah data primer dan data sekunder. Teknik pengumpulan data dilakukan dengan cara wawancara mendalam, observasi, dan dokumentasi. Teknik triangulasi sumber digunakan untuk untuk mengembangkan validitas penelitian. Sedangkan untuk teknik analisis data dilakukan dengan pengumpulan data, reduksi data, sajian data, dan penarikan kesimpulan sehingga sebuah kesimpulan penelitian dapat dilakukan

\section{Hasil Penelitian dan Pembahasan}

Strategi customer relations yang dilaksanakan oleh Hotel Cakra Kusuma Yogyakarta adalah dengan melakukan pelayanan kepada pelanggan dimana melibatkan dukungan oleh segenap karyawan perusahaan. Hal ini dikarenakan bahwa untuk menciptakan suatu kepuasan pelanggan, perusahaan harus dapat memberikan pelayanan secara baik (good service) sesuai dengan harapan dan keinginan pelanggan Hotel Cakra Kusuma Yogyakarta. Menurut Payne dalam Tjiptono (2004:128) pelanggan adalah orang yang membeli barang atau jasa perusahaan. Pelanggan adalah orang yang paling penting bagi suatu usaha atau organisasi, orang yang menyampaikan segala keinginan dan harapannya serta orang yang menentukan sukses sebuah perusahaan dan para pekerjanya. Suatu tujuan organisasi dapat tercapai apabila harapan dari seorang pelanggan akan terpenuhi. Jika harapan pelanggan dapat terpenuhi, maka kepuasan pelanggan dapat tercipta atas hasil kinerja perusahaan yang dirasakan langsung oleh pelanggan.

Keberhasilan strategi customer relations Hotel Cakra Kusuma Yogyakarta dapat dicapai dengan didukung segenap karyawan di seluruh departemen yang ada di Hotel Cakra Kusuma Yogyakarta untuk melaksanakan tugas-tugasnya secara profesional. Para petugas pelaksana perusahaan seperti karyawan, public relations, adalah merupakan ujung tombak perusahaan dalam pelaksanaan strategi customer relations Hotel Cakra Kusuma Yogyakarta dalam usaha perusahaan meningkatkan pelanggan.

Untuk mewujudkan suatu customer rela- 
Tabel 1 Program strategi Customer Relations

Hotel Cakra Kusuma Yogyakarta

\begin{tabular}{|c|c|c|}
\hline No & Program yang dilaksanakan & Sasaran yang dituju \\
\hline 1 & Program Kesetiaan Pelanggan & Pelanggan \\
\hline 2 & Special Event Packages & Pelanggan calon pelanggan \\
\hline 3 & Relationship Action & $\begin{array}{l}\text { Pelanggan yaitu Travel } \\
\text { Agent,Corporate, } \\
\text { Government, Public }\end{array}$ \\
\hline 4 & Pemberian Penghargaan & Travel Agent, Personal \\
\hline 5 & Menetapkan kebijaksanaan harga & Pelanggan \\
\hline 6 & Program Promotion & $\begin{array}{l}\text { Pelanggan dan } \\
\text { calon pelanggan }\end{array}$ \\
\hline 7 & Long Stay Package & $\begin{array}{l}\text { Pelanggan } \\
\text { calon pelanggan }\end{array}$ \\
\hline 8 & Menambah menu makanan & Pelanggan dan calon pelanggan \\
\hline
\end{tabular}

Sumber: Data dari dokumen 2009 Hotel Cakra Kusuma Yogyakarta

tions yang baik antara pihak hotel dan para pelanggan, terlebih dahulu langkah penting awal bagi pihak Hotel adalah harus memahami dan mengerti makna dari arti kata pelanggan. Pelanggan bukanlah orang yang semata-mata sering datang ke Hotel, namun pelanggan adalah orang yang menaruh harapan dan membiarkan pihak Hotel untuk mewujudkan harapan dan keinginannya. Pelanggan adalah orang yang dipengaruhi agar berbuat suatu tindakan tertentu. Jika terjadi suatu ketidaknyamanan maka pihak Hotel harus segera mengetahui dan menindaklanjuti, karena seorang pelanggan memiliki hak penuh kepada dirinya sendiri untuk melakukan komplain secara langsung ataupun diputuskan hanya akan dipendam sendiri. Jika pihak Hotel tidak membuat jembatan komunikasi interaktif kepada pelanggan, maka akan sangat fatal nantinya terlebih lagi jika hal kenyamanan tersebut disampaikan kepada orang lain Penulis menggunakan kajian komunikasi organisasi untuk melihat pentingnya fungsi public relations dalam suatu organisasi. Hasil penelitian menunjukkan bahwa untuk meningkatkan kepuasan pelanggan adalah dengan kegiatan customer relations.

Kegiatan customer relations yang dijalankan oleh Hotel Cakra Kusuma Yogyakarta yaitu dengan melibatkan seluruh staff dan karyawan hingga pimpinan manager untuk melaksanakan tugas dan kewajibannya masing-masing secara professional. Hotel Cakra Kusuma Yogyakarta telah melaksanakan perencaaan dan pelaksanaan strategi customer relations yang terdiri dari defining the problems, planning programming, taking action, dan evaluating. Sejauh ini para pelanggan cukup puas dengan pelayanan yang diberikan oleh Hotel Cakra Kusuma Yogyakarta Hotel Cakra Kusuma Yogyakarta telah mampu memanfaatkan faktor pendukung dengan adanya kegiatan customer relations yang efektif dalam kaitannya pembinaan hubungan dengan pelanggan dan stakeholder yang membawa dampak bagi peningkatan tingkat hunian kamar dan hubungan baik yang telah terbina. Namun faktor internal seperti peningkatan kualitas SDM dalam pengkomunikasian informasi, keterbatasan karyawan, dan renovasi masih perlu dilakukan untuk peningkatan kepuasan pelanggan hingga dapat menjadi investasi jangka panjang bagi perusahaan. Hotel Cakra Kusuma harus segera melakukan perbaikan dan renovasi di sektor-sektor yang minim agar kepuasan pelanggan dapat tercapai. Penerapan customer relations di sebuah Hotel dalam meningkatkan kepuasan pelanggan adalah dengan membuat seorang tamu atau pengunjung menjadi puas dan nyaman sehingga diharapkan akan datang kembali lagi dan menjadi seorang pelanggan yang loyal 
karena komitmen dan pelaksanaan customer relations yang efektif.

Fokus utama perhatian dalam customer relations hotel dalam penelitian ini adalah apabila pelanggan puas maka akan tercipta citra positif yang disebabkan oleh pelayanan mutu yang baik sehingga diharapkan akan datang kembali lagi dan menjadi pelanggan yang loyal. Customer relations menyangkut bidang suatu hubungan antara pelanggan dengan perusahaan. Perusahaan sangat menyadari bahwa tanpa konsumen tidak akan berarti apa-apa. Dengan kata lain, konsumen merupakan peranan penting bagi suatu perusahaan, tanpa konsumen maka suatu kesempatan bisnis akan hilang. Oleh karena itu, seluruh ruang usaha dalam hal ini suatu hotel harus dapat menyadari bahwa : (a) pelanggan adalah orang yang paling penting bagi suatu ruang usaha; (b) pelanggan tidak tergantung pada ruang usaha tersebut, melainkan ruang usaha sangat bergantung pada para pelanggan; (c) pelanggan merupakan sumber pendapatan dan juga sumber keuntungan. Tanpa pelanggan, pendapatan dan keuntungan suatu ruang usaha tidak mungkin diperoleh; (d) pelanggan adalah orang yang akan membayar gaji, upah, dan honor bagi karyawan maupun owner. Oleh sebab itu, mengapa selalu dikatakan " $\mathrm{Cus}$ tomer Is The Boss" bila seluruh karyawan maupun owner sekalipun tidak memberikan pelayanan yang maksimal maka pelanggan akan hilang begitu saja dengan rasa kecewa dan membuat citra hotel menjadi negatif.

Strategi customer relations dalam peningkatan kepuasan pelanggan di Hotel Cakra Kusuma Yogyakarta terbagi menjadi dua yaitu tahap perencanaan pembuatan program serta menentukan sasaran potensial yang akan dituju menggunakan teori manajemen relasi dari John Ledingham dan Steven Burning. Teori ini menyoroti bentuk hubungan yang dilakukan organisasi terhadap Market, Audience, Public (MAP). Seperti program customer relations yang ditujukan untuk pelanggan personal yaitu adanya previllage card dan pelayanan maksimal selama tamu tersebut menginap di Hotel. Sedangkan untuk travel agent atau corporate penerapan program customer relations dilakukan dengan pemberian harga khusus dan pembinaan hubungan baik dengan melakukan kegiatan-kegiatan interaktif bersama para pelanggan seperti pemberian penghargaan, sales blitz dan event penting yang diadakan perusahaan. Program customer relations hotel Cakra Kusuma Yogyakarta ditujukan untuk pelanggan dan calon pelanggan. Pelanggan adalah corporate, travel agent, atau personal yang sering melakukan transaksi jasa di Hotel Cakra Kusuma Yogyakarta. Para pelanggan tersebut juga mendapat perlakuan khusus misalnya adanya memberd card, pemberian harga khusus, pelayanan VIP atau VVIP dan relationship action. Sedangkan calon pelanggan adalah semua yang orang yang berkunjung ke Hotel Cakra Kusuma Yogyakarta. Misalnya dengan adanya program customer relations yaitu special event tertentu, promosi makanan dan cold call. Untuk segmen calon pelanggan program customer relations tersebut bersifat sebagai pengenalan informasi mengenai Hotel Cakra Kusuma Yogyakarta. Mengelola calon pelanggan adalah penting, karena disitulah bagaimana pihak Hotel Cakra Kusuma Yogyakarta mengadakan komunikasi dengan calon pelanggan yang nantinya diharapkan akan jadi pelanggan. Calon pelanggan menilai pada tahap awal yaitu bagaimana keramahtamahan para staff dan karyawan hotel dalam memberikan pelayanan yang maksimal meskipun calon pelanggan tersebut belum menggunakan jasa kamar Hotel Cakra Kusuma Yogyakarta.

Sedangkan hasil pelaksanaan customer relations Hotel Cakra Kusuma Yogyakarta terhadap para pelanggannya sesuai dengan teori word of mouth (WoM) yaitu kepuasan merupakan faktor yang akan mendorong adanya komunikasi dari mulut ke mulut (word of mouth communication). Pelanggan yang puas akan berbagi cerita dan pengalamannya terhadap orang lain, selain itu pelanggan yang puas tidak hanya akan membeli kembali namun juga berfungsi sebagai papan iklan gratis dengan biaya yang rendah. Pentingnya word of mouth bagi pemasar suatu jasa atau produk, kepuasan pelanggan atas pengaruh teman dan secara relatif akan membeli, ketidakpuasan konsumen akan menghalangi penjualan. Harapan pelanggan yang paling sederhana adalah berbentuk asumsi. Calon pelanggan dan pelanggan memiliki harapan yang sederhana agar mereka dapat 
istirahat dengan nyaman dan aman selama berada di Hotel Cakra Kusuma Yogyakarta. Untuk calon pelanggan tahap pertama mereka mereka merasa terkesan dengan pelayanan dan keramahtamahan para staff dan karyawan. Dari beberapa sumber yang diwawancarai oleh peneliti memperlihatkan bahwa kesan pertama akan menentukan untuk ke depannya apakah mereka akan mengadakan kerjasama dengan Hotel Cakra Kusuma Yogyakarta kembali atau tidak. Jika dari awal mereka merasakan ketidaknyamanan selama berada di Hotel Cakra Kusuma Yogyakarta maka besar kemungkinan mereka tidak akan kembali lagi apalagi untuk menggunakan jasa dari Hotel Cakra Kusuma Yogyakarta.

Penerapan slogan care and smile telah diterapkan secara maksimal oleh seluruh karyawan Hotel Cakra Kusuma Yogyakarta yang dapat dirasakan langsung oleh pelanggan dan calon pelanggan yang datang. Motto care and smile merupakan upaya pendekatan personal dalam pembinaan hubungan baik kepada pelanggan. Jika dari awal telah tercipta hubungan yang positif maka untuk selanjutnya akan terbina peningkatan hubungan dan melakukan suatu tindakan selanjutnya oleh calon pelanggan yang akan memberikan dampak positif bagi perusahaan. Keterbukaan diri yang bersifat timbal balik pada tahap awal suatu hubungan. Adanya informasi yang jelas dan komunikasi dua arah yang terjalin dapat menumbuhkan kepercayaan dalam benak pelanggan atau calon pelanggan dalam penerapan customer relations hotel cakra kusuma Yogyakrta. Sosialisasi mengenai adanya program customer relations telah berjalan secara baik misalnya dengan pemberian kebijakan harga khusus, pemberian cindera mata dan paket-paket promo yang diselenggarakan. Keterbukaan ini dari pihak Hotel Cakra Kusuma Yogyakarta sebagai langkah awal strategis bagaimana pihak hotel menginformasikan adanya program customer relations ini melalui email campaign, brosur, flyer, banner dan personal selling. Suatu hubungan akan menjadi lebih dekat ketika pengetahuan dan pemahaman akan informasi dapat diterima dengan baik dan terjadi perkembangan jelasnya yaitu proses peningkatan kedekatan suatu hubungan yaitu dari calon pelanggan menjadi pelanggan yang loyal sehingga kesan dan pengalaman baik dapat dirasakan secara langsung oleh pelanggan dan calon pelanggan.

Namun penulis menemukan kenyataan bahwa alangkah baiknya jika pelanggan personal juga mendapatkan perhatian yang sama misalnya ucapan selamat ulang tahun, thank you latter, tidak hanya untuk pelanggan corporate adapun travel agent saja. Potensi pelanggan personal ini bisa saja dapat berubah karena kurangnya perhatian dari perusahaan dan komunikasi persuasif yang stabil bagi pelanggan. Pelanggan personal memang mendapatkan pula pelayanan maksimal selama dia menginap, pemberian cinderamata, dan fasilitas previllage card. Namun pembinaan hubungan ke depan tidak dilakukan dan hanya berhenti pada tahap selama dia tinggal dan menggunakan jasa dari Hotel Cakra Kusuma Yogyakarta saja.

Hal tersebut dapat membuat pelanggan menjadi lupa dan tidak merasa memiliki kedekatan dengan pihak Hotel meskipun telah memliki kartu member namun karena tidak ada komunikasi yang secara terus menerus dari pihak hotel kepada pelanggan, maka dapat membuat Hotel Cakra Kusuma Yogyakarta kehilangan keterikatan personal dengan para pelanggannya. Jika ternyata mampu melewati dalam tahap ini untuk selanjutnya pembinaan hubungan baik antara pihak Hotel dengan pelanggannya akan dapat tercipta hubungan yang lebih stabil, lebih bermakna dan lebih bertahan lama Karena merawat suatu hubungan itu lebih sulit daripada mencari hubungan baru. Selain itu, penulis menemukan kenyataan pula bahwa beberapa customer merasakan ketidakpuasan terhadap fasilitas kamar standard untuk ukuran sebuah Hotel bintang tiga. Kemungkinan para customer untuk tidak kembali lagi sangatlah mungkin apabila renovasi kamar tidak segera dilakukan oleh pihak Hotel Cakra Kusuma Yogyakarta. Selain kamar standard yang tidak memenuhi harapan pelanggan, tidak adanya sarana atau media keluhan pelanggan dalam bentuk kuisioner tertulis menyebabkan terjadinya hambatan komunikasi dalam penyampaian keluhan pelanggan. Keluhan pelanggan ini bersifat pribadi dan pelanggan memiliki hak penuh untuk menyampaikan kepada pihak Hotel atau tidak. 
Apakah nantinya akan dipendam sendiri, disampaikan kepada hotel ataupun akan menceritakannya kepada orang lain. Hal seperti ini dapat menjadi bom waktu yang dapat merusak citra positif hotel secara keseluruhan. Terlebih lagi jika keluhan pelanggan tersebut tidak segera ditanggapi dengan cepat dan tanggap maka akan terjadi depenetrasi yaitu kehilangan pelanggan bagi Hotel Cakra Kusuma Yogyakarta.

Teori Word of Mouth Communication dapat memperlihatkan dua sisi yang berbeda yaitu positif atau negatif berdasarkan pengalaman dan persepsi yang diterima dan dirasakan oleh pelanggan maupun calon pelanggan. Promosi dari mulut ke mulut yang mengandung nilai positif akan tercipta apabila pelanggan merasa puas atas pelayanan yang diberikan hotel maupun dapat merasakan adanya perhatian penuh dari hotel Cakra Kusuma Yogyakarta terhadap para pelanggan dilihat dari kegiatan customer relations yang telah dilaksanakan. Sedangkan citra negative akan tercipta apabila pelanggan tidak merasakan kenyamanan selama menggunakan jasa atau produk dari Hotel Cakra Kusuma Yogyakarta serta kelemahan dan kekurangan yang dimilki oleh Hotel Cakra Kusuma Yogyakarta tidak segera ditindak lanjuti dan disikapi dengan cepat dan tanggap. Pengalaman yang kurang menyenangkan dari pelanggan ini akan menjadi ancaman yang dapat merusak citra perusahaan jika pelanggan tersebut menceritakan kepada orang lain.

Dalam menentukan suatu langkah-langkah dan penerapan staretegi customer relations public relations Hotel Cakra Kusuma Yogyakarta melakukan empat langkah manajemen public relations yaitu defining the problems, planning and programming, taking action, dan evaluation. Dalam kegiatan defining the problem yaitu pihak public relations menganalisa sebuah masalah, peluang dan kesempatan, peka dan tanggap terhadap perubahan-perubahan informasi sosial masyarakat yang arus informasinya sangat cepat dengan menentukan sasaran-sasaran potensial yang akan dituju. Mempersiapkan materi promosi yang menarik: brosur, flyer yang menarik sesuai dengan calender of event, calender of academic dan musim liburan. Misalnya, mengetahui kondisi di Yogyakarta yang pada bulan-bulan tertentu terdapat events meriah baik yang diselenggarakan oleh pemeritah, universitas, event organizer, dan lain-lain. Disini public relations telah mempunyai pemikiran bahwa pada saat event tersebut maka jumlah pendatang di Yogyakarta baik itu masyarakat maupun wisatawan akan mengalami kenaikan. Oleh karena itu, pihak Public Relations dan manajemen membuat program-program menarik yang sebelumnya telah dipromosikan terlebih dulu melalui iklan dan kunjungan sales-sales ke corporate atau travel agent serta melakukan pengumpulan fakta dengan mengetahui sampai sejauh mana tingkat kepuasan pelanggan atas pelayanan yang telah diberikan perusahaan. Kegitan planning and programming penentuan sasaran program customer relations yang berkaitan dengan pelaksanaan program nantinya. Informasi yang telah diperoleh sebelumnya kemudian digunakan untuk membuat keputusan tentang program public, tujuan, aksi dan strategi, serta taktik adan sasaran yang akan ditetapkan. Sasaran publik manakah yang akan dituju serta menetapkan tujuan untuk masingmasing publik yang akan dituju dari penerapan pelaksanaan program customer relations perusahaan dalam meningkatkan kepuasan pelanggan.

Tujuan dengan diadakannya program customer relations di Hotel Cakra Kusuma adalah menjaga dan meningkatkan hubungan positif antara perusahaan dengan pelanggan, stakeholder yang selama ini mendukung dan bekerja sama dengan perusahaan. Sasaran dari program customer relations ini adalah calon pelanggan dan pelanggan yaitu travel agent, corporate, dan pelanggan personal. Kegiatan bersama ini telah efektif dengan mengadakan kerjasama dan pemberian penghargaan kepada travel agent serta perlakuan istimewa dengan memberikan harga dan pelayanan khusus kepada corporate atau travel agent dan pemberian cindera mata yang kepada pelanggan tertentu yang telah memberikan pemasukan banyak bagiperusahaan. Kegiatan Taking Action and Communicating adalah tujuan dan publik yang ditentukan untuk mencapai tujuan-tujuan program customer relations yang telah ditetapkan melalui kegiatan komunikai dengan publik sasaran. Pentingnya program tindakan yang dilakukan $p u b$ lic relations dalam rangka pelaksanaan strategi 
customer relations merupakan usaha untuk dapat memelihara hubungan yang baik dengan pelanggan dan public. Tahapan ini menjelaskan mengenai informasi dan langkah-langkah yang akan dilakukan, sehingga mampu menimbulkan kesankesan yang positif dan program bagi pelanggan potensial dalam upaya memberikan dukungan sepenuhnya terhadap Hotel Cakra Kusuma Yogyakarta.

Oleh karena itu, kepuasan pelanggan dapat tercipta jika dilandasi oleh hubungan yang yang harmonis dan saling menguntungkan antara Hotel Cakra Kusuma dengan pelanggan. Pihak Cakra Kusuma Yogyakarta telah efektif dalam menginformasikan dan memberitahukan pelanggan apa saja program yang dibuat oleh Hotel Cakra Kusuma Yogyakarta melalaui iklan seperti email, brosur, banner, dan penyampaian langsung dari front office kepada pelanggan, membuat paket-paket promosi untuk tiap program yang di selenggarakan, menjalin good relationship dengan berbagai phak yang berkaitan dengan pelaksanaan strategi customer relations Hotel Cakra Kusuma Yogyakarta dalan meningkatkan kepuasan pelanggan seperti : tamu hotel, pelanggan, calon pelanggan, agen-agen perjalanan, pemerintah daerah, instansi, pihak asuransi, Dinas Pariwisata Yogyakarta, dan lainlain. Perusahaan juga telah melakukan pendekatan pribadi (personal approach) dengan cara mendatangi instansi-instansi untuk memberi penawaran atas jasa Hotel.

\section{Simpulan}

Tugas dan kewajiban masing-masing staff dan karyawan dalam melaksanakan customer relations yang dilakukan secara profesional oleh segenap karyawan Hotel Cakra Kusuma Yogyakarta hingga pimpinan Manager. Pelaksanaan customer relations yang konsisten dan komunikasi yang saling terbuka dan interaktif dengan para pelanggan maupun calon pelanggan merupakan kunci utama dalam keberhasilan suatu program customer relations Hotel Cakra Kusuma Yogyakarta dalam meningkatkan kepuasan pelanggan. Strategi customer relations yang dilakukan oleh Hotel Cakra Kusuma Yogyakarta adalah meliputi program customer relations seperti pembuatan member card bagi pelanggan, pemberian cindera mata atau souvenir kepada pelanggan, membuat program atau special event antara pihak hotel dengan pelanggan sepertitravel agent, corporate, dan pelanggan personal agar hubungan dengan pelanggan berjalan baik dan akrab. Selain itu pembenahan fasilitas fisik, penanganan keluhan misalnya penanganan keluhan secara langsung (face to face) melalui kayawan dan staff hotel, kegiatan promosi dan penyampaian informasi tentang suatu event atau adanya paket-paket baru menjadi strategi customer relations yang efektif bagi hotel Cakra Kusuma Yogyakarta dalam meningkatkan kepuasan pelanggan.

\section{Daftar Pustaka}

Assael, Henry, 1998, Consumer behavior and marketing communication, Jakarta.

Heath, LRobert dan W Timothy Coombs, 2006, Today's Public Relations An Introduction. SAGE Publications, United States Of America.

Moleong, Lexy J., 1996, Metode Penelitian Kualitatif, PT Remaja Rosdakarya, Bandung.

Ruslan, Rosaday, 2006, Manajemen Public Relations dan Media Komunikasi, Konsepsi dan Aplikasi, PT Raja Grafindo Perkasa, Jakarta.

Tjiptono, Fandy, 2004, Prinsip-pronsip Total Quality Service, Andi Offsheet, Yogyakarta. 